\title{
Can Orbital Cavity Be Used to Estimate Stature in Human Identification?
}

\author{
Antonio Azoubel Antunes', Andreza Alexandre da Paz de Souza², \\ Breno Henrique Mara Rodrigues ${ }^{1}$, Romeyka Karinny Almeida de Freitas ${ }^{1}$, \\ Marcus Vitor Diniz de Carvalho ${ }^{1}$, Evelyne Pessoa Soriano ${ }^{1}$, Gabriela Granja Porto ${ }^{*}$ \\ ${ }^{1}$ Forensic Sciences, University of Pernambuco (UPE), Recife, Brazil \\ ${ }^{2}$ Faculty of Dentistry, University of Pernambuco (UPE), Recife, Brazil \\ Email: ^gabriela.porto@upe.br
}

How to cite this paper: Antunes, A. A., da Paz de Souza, A. A., Rodrigues, B. H. M., de Freitas, R. K. A., de Carvalho, M. V. D., Soriano, E. P., \& Porto, G. G. (2021). Can Orbital Cavity Be Used to Estimate Stature in Human Identification? Advances in Anthropology, 11, 1-12.

https://doi.org/10.4236/aa.2021.111001

Received: December 4, 2020

Accepted: January 31, 2021

Published: February 3, 2021

Copyright $\odot 2021$ by author(s) and Scientific Research Publishing Inc. This work is licensed under the Creative Commons Attribution International License (CC BY 4.0).

http://creativecommons.org/licenses/by/4.0/

(c) (i) Open Access

\begin{abstract}
Objectives: To establish the correlation between orbital measurements and the height of individuals of a Brazilian population for human identification and height estimation. Materials and Methods: The sample consisted of 100 patients of both sexes, from Brazil Northeast, who sought the radiology service of the Oswaldo Cruz University Hospital to undergo facial CT for other purposes. Sex and stature of each subject were obtained on this occasion. After data collection, the craniometric points were determined and tomographic measurements were taken, correlating the findings with the variables studied. Results: Sixty-four (64.3\%) of the participants were male and 36 (35.7\%) were female. Stature was significantly greater in men than in women. The two variables had positive coefficients and were significant $(p<0.001)$, with female sex being used as the reference. The coefficient of determination was 0.435 , indicating a reasonable fit of the model to the data. The orbit measurements can be accurate on estimating male and female stature in $83 \%$. Conclusion: The orbit is an effective parameter for the estimation of stature from images of bone remains for human identification, in which linear orbital measurements can be correlated with anthropometric data (sex, and stature). An equation was proposed for estimating a subject's stature in the population studied.
\end{abstract}

\section{Keywords}

Anthropometric Measurements, Orbit, Human Identification, Height, Body, Sex Characteristics

\section{Introduction}

Stature estimation is an objective tool for the identification of human remains 
(Bidmos, 2008). Different equations derived from the relationship between limb height and bone length have been used to reconstruct stature in skeletal samples (Raxter et al., 2006; Belmonte et al., 2011; Gidna \& Domínguez-Rodrigo, 2013; Weaver et al., 2010; Pereira et al., 2019).

Some height estimation methods using long bones, cranium, and spinal vertebrae have been developed and applied to different populations. The main problem encountered is that the methods are developed for a given population and cannot be applied to another with different races and miscegenation (Belmonte et al., 2011). In countries like Brazil, which is characterized by widespread racial miscegenation, this evaluation is difficult because of the lack of standards and methods used in this population for human identification. To minimize such problems, population studies are necessary to obtain in-depth knowledge of the variables that affect the population studied.

Studies suggest that the orbit widens with age and that significant relations exist between a subject's height and orbital measurements, and eye location. The association of these measurements with height may indicate an effect of other factors, such as age, sex, and ancestry in orbit anthropometry (Krishan, 2008; Telkkã, 1950).

Krishan (2008), studying 996 men from north India, showed that regression analysis could be used to successfully estimate stature from different cephalo-facial dimensions when cephalo-facial remains are brought in for forensic examination. In similar studies, Kamal \& Kumar (2016) and Sahni et al. (2010) concluded that regression equations derived from facial measurements could be a supplementary approach to estimating stature when extremities are not available.

The correlation of orbital measurements with a subject's stature can provide important data for elaborating an equation that can be used in height estimation during the process of identification. Within this context and based on the studies mentioned above, we believe that the proposal of an equation derived from orbital measurements related to Brazilian individuals' height and sex would be useful for stature estimation in cases of human identification in this population.

\section{Methods}

This cross-sectional, prospective, analytical study was conducted in individuals older than 20 years old, from the state of Pernambuco, Northeast Brazil, who spontaneously sought the medical radiology service for cranial or facial computed tomography assessment for other purposes, and met all of the inclusion criteria established to participate in this study. Individuals with facial trauma, a history of any diseases involving the eyes or orbits, and those with a history of surgery who exhibited artifacts on tomographic scans were excluded from the study. In addition to the imaging examination, we collected sex, age, and height according to the participants' term informed consent and privacy rights. Each participant's stature was measured in centimeters as the vertical distance from the ground to the vertex. 
The sample size was calculated with the GPOWER ${ }^{\circledR}$ 3.1.9.2 software (1992-2014) using a data source of variables similar to those of the study of Ji et al. (2010). The mean and standard deviation of orbital roof length in females and males were used for this calculation. We chose these variables because it showed a significant difference and had a larger sample than the other variables. The estimated sample size was 94 patients, with a power of analysis of 0.90424 , considering a significance level of 0.05 .

The participants were invited to have their height measured by a unique examiner who did not participate in the CT scans measurements. Data was recorded and saved for the linear regression statistical analysis.

The tomographic images obtained were visualized with the InVesalius ${ }^{\circledR} 3.0$ program (public-domain software, Brazil), and the position and orientation of the head planes were adjusted, observing the skull and orbital cavities through $3 \mathrm{D}$ reconstructions. The anatomical landmarks of the orbit were determined with the measurement tools of the program (Figure 1), and the orbital cavity measurements were then taken (Table 1).

The linear measurements were obtained by an independent and well-trained evaluator different from the person who collected the sex and age data, following the recommendations of Ji et al. (2010). Examiner calibration was performed following the method of Dangour (Belmonte et al., 2011). For this purpose, ten subjects were taken as a reference, and their measurements were obtained twice on different occasions at a minimum interval of 15 days. The values obtained with this double measurement were compared. Moreover, it was determined whether

Table 1. Definition of anatomical landmarks of the orbit and relevant length parameters.

\begin{tabular}{|c|c|}
\hline Anatomical landmark/length & Definition \\
\hline Maxillofrontal point (Mf) & $\begin{array}{l}\text { The junction between the frontomaxillary suture and medial } \\
\text { orbital rim }\end{array}$ \\
\hline Ectoconchion point $(\mathrm{Ec})$ & $\begin{array}{l}\text { The junction between the lateral orbital rim and the horizontal } \\
\text { line that divides the orbital foramen into two equal parts }\end{array}$ \\
\hline Supraorbital point (Os) & $\begin{array}{l}\text { The superior junction between the superior orbital rim and the } \\
\text { perpendicular bisector line of line Mf-Ec }\end{array}$ \\
\hline Infraorbital point (Oi) & $\begin{array}{l}\text { The inferior junction between the inferior orbital rim and the } \\
\text { perpendicular bisector line of line Mf-Ec }\end{array}$ \\
\hline Optic foramen point (Of) & Optic foramen \\
\hline Orbital breadth & Mf-Ec \\
\hline Orbital height & Os-Oi \\
\hline Medial wall length & Mf-Of \\
\hline Lateral wall length & Ec-Of \\
\hline Orbital roof length & Os-Of \\
\hline Orbital floor length & Oi-Of \\
\hline Intraorbital distance (IOD) & Mf-Mf \\
\hline Extraorbital distance (EOD) & $\mathrm{Ec}-\mathrm{Ec}$ \\
\hline
\end{tabular}




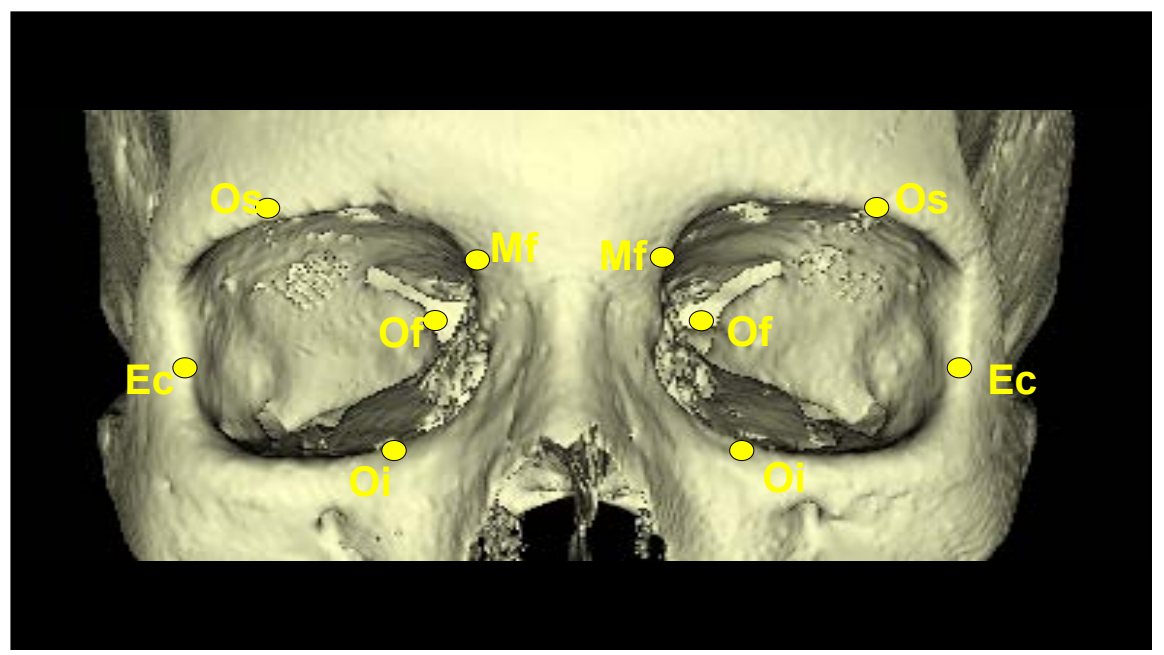

Figure 1. Anatomical landmarks of the orbit used for the measurements.

they were within the established limits using statistical tests, indicating if the measurements would be reproducible (kappa $=0.89$ ).

The data were analyzed descriptively using absolute and relative frequencies. Numerical variables are reported as mean, standard deviation, and median. For inferential analysis, the parametric Student t-test and paired Student t-test were applied to normally distributed data and the Mann-Whitney and Wilcoxon tests for paired data if the data were not normally distributed. The normality of the data and homogeneity of variances were verified using the Shapiro-Wilk test and Levene's F test, respectively.

For height estimation, two linear regression models were fitted to the measurements and sex as an independent variable. The regression equation, variables' significance, coefficient of determination $\left(R^{2}\right)$, the model's significance, and normality of residuals were obtained. All measurements and sex were included in the first model. For the other model, a backward selection of the variables was used, with $p=0.10$ entering and remaining in the model.

A margin error of $5 \%$ was used in the statistical test decisions. The Statistical Package for the Social Sciences v21 (SPSS) was used to tabulate the data and statistical analysis.

\section{Results}

One hundred patients were selected; sixty-four (64.3\%) were male, and 36 (35.7\%) female. The mean height was $1.71 \pm 0.07 \mathrm{~m}$ in men, $1.61 \pm 0.06$ in women, and $1.67 \pm 0.08 \mathrm{~m}$ for both sexes. The comparison showed greater mean heights in male participants compared to females.

Table 2 shows the mean and standard deviation of the orbital and interorbital measurements in the whole sample and according to sex. Significant differences $(p<0.05)$ between sexes were observed for MF-EC and EC-OF on the right side and for MF-EC on the left side, with the mean values being higher in men. Variability was low since the standard deviations were less than $1 / 3(33.3 \%)$ of the 
Table 2. Statistical analysis of right and left orbital and interorbital measurements in the whole sample and according to sex.

\begin{tabular}{|c|c|c|c|c|}
\hline \multirow[b]{2}{*}{ Variable } & \multicolumn{2}{|c|}{ Sex } & \multirow[b]{2}{*}{ Whole sample } & \multirow[b]{2}{*}{$p$-value } \\
\hline & Male $(n=64)$ & Female $(n=36)$ & & \\
\hline & Mean \pm SD & Mean \pm SD & Mean \pm SD & \\
\hline \multicolumn{5}{|c|}{ Right orbit } \\
\hline Mf-Ec & $34.94 \pm 2.39$ & $33.59 \pm 1.93$ & $34.41 \pm 2.32$ & $0.005^{*(1)}$ \\
\hline Os-Oi & $34.55 \pm 2.86$ & $33.78 \pm 2.66$ & $34.24 \pm 2.78$ & $0.198^{(1)}$ \\
\hline Mf-Of & $17.78 \pm 2.67$ & $17.68 \pm 2.78$ & $17.66 \pm 2.74$ & $0.867^{(1)}$ \\
\hline Ec-Of & $19.23 \pm 4.39$ & $17.67 \pm 3.98$ & $18.77 \pm 4.30$ & $0.011^{\star^{(2)}}$ \\
\hline Os-Of & $20.36 \pm 4.58$ & $18.97 \pm 4.33$ & $20.07 \pm 4.70$ & $0.146^{(2)}$ \\
\hline Oi-Of & $16.72 \pm 2.48$ & $16.87 \pm 2.45$ & $16.71 \pm 2.48$ & $0.730^{(2)}$ \\
\hline \multicolumn{5}{|l|}{ Left orbit } \\
\hline Mf-Ec & $34.63 \pm 4.90$ & $33.90 \pm 2.33$ & $34.28 \pm 4.22$ & $0.026^{\star(2)}$ \\
\hline Os-Oi & $34.17 \pm 4.88$ & $34.18 \pm 3.12$ & $34.09 \pm 4.38$ & $0.565^{(2)}$ \\
\hline Mf-Of & $17.60 \pm 2.66$ & $17.85 \pm 4.29$ & $17.62 \pm 3.35$ & $0.521^{(2)}$ \\
\hline Ec-Of & $19.65 \pm 4.77$ & $18.11 \pm 4.91$ & $19.20 \pm 4.86$ & $0.144^{(2)}$ \\
\hline Os-Of & $19.74 \pm 4.18$ & $18.85 \pm 3.60$ & $19.54 \pm 4.09$ & $0.428^{(2)}$ \\
\hline Oi-Of & $16.82 \pm 2.42$ & $16.25 \pm 2.68$ & $16.54 \pm 2.55$ & $0.286^{(1)}$ \\
\hline \multicolumn{5}{|c|}{ Interorbital } \\
\hline MF-MF & $33.22 \pm 3.72$ & $33.22 \pm 3.87$ & $33.27 \pm 3.74$ & $0.998^{(1)}$ \\
\hline EC-EC & $91.35 \pm 11.55$ & $89.03 \pm 14.56$ & $90.40 \pm 12.59$ & $0.175^{(2)}$ \\
\hline \multicolumn{5}{|c|}{ Both orbits } \\
\hline Mf-Ec & $34.78(2.92)$ & $33.74(1.64)$ & $34.34(2.62)$ & $0.005^{\star(3)}$ \\
\hline Os-Oi & $34.36(3.25)$ & $33.98(2.66)$ & $34.16(3.07)$ & $0.326^{(3)}$ \\
\hline Mf-Of & $17.69(2.48)$ & $17.76(3.00)$ & $17.64(2.69)$ & $0.959^{(3)}$ \\
\hline Ec-Of & $19.44(4.40)$ & $17.89(4.20)$ & $18.98(4.38)$ & $0.042^{\star(3)}$ \\
\hline Os-Of & $20.05(4.26)$ & $18.91(3.91)$ & $19.80(4.26)$ & $0.299^{(3)}$ \\
\hline Oi-Of & $16.77(2.17)$ & $16.56(2.39)$ & $16.62(2.28)$ & $0.630^{(3)}$ \\
\hline
\end{tabular}

$\left.{ }^{*}\right)$ : Significant difference at the $5 \%$ level; (1): Student t-test with equal variances; (2): Mann-Whitney test; (3): Mann-Whitney test.

corresponding means. This table also shows the orbital measurements independent of the side, which were obtained as the average of the two sides. Significant differences between sexes were found for MF-EC and EC-OF variables, with the mean values being higher in men $(34.78 \times 33.74$ for MF-EC and $19.44 \times 17.78$ for $\mathrm{EC}-\mathrm{OF}$ ).

The correlations between stature and each of the orbital and interorbital measurements are shown in Table 3. The only correlations significantly different from zero were observed for stature with MF-EC in the right and left orbits, 
Table 3. Correlation between the right, left, interorbital measurements, and orbital measurements independent of side.

\begin{tabular}{|c|c|c|}
\hline Variable & Stature & Stature \\
\hline & $r(p)$ & $r(p)$ \\
\hline Right orbit & & Both orbits \\
\hline Mf-Ec & $0.307(0.002)^{\star(1)}$ & $0.330(0.001)^{*}$ \\
\hline Os-Oi & $0.086(0.393)^{(2)}$ & $0.056(0.580)$ \\
\hline Mf-Of & $0.100(0.321)^{(2)}$ & $0.088(0.384)$ \\
\hline Ec-Of & $0.206(0.039)^{\star(2)}$ & $0.169(0.093)$ \\
\hline Os-Of & $0.061(0.547)^{(2)}$ & $0.020(0.841)$ \\
\hline Oi-Of & $-0.012(0.907)^{(2)}$ & $0.085(0.402)$ \\
\hline \multicolumn{3}{|l|}{ Left orbit } \\
\hline Mf-Ec & $0.256(0.010)^{\star(2)}$ & \\
\hline Os-Oi & $0.036(0.724)^{(2)}$ & \\
\hline Mf-Of & $0.092(0.363)^{(2)}$ & \\
\hline Ec-Of & $0.123(0.224)^{(2)}$ & \\
\hline Os-Of & $-0.005(0.959)^{(2)}$ & \\
\hline Oi-Of & $0.130(0.198)^{(1)}$ & \\
\hline \multicolumn{3}{|l|}{ Interorbital } \\
\hline Mf-Mf & $0.110(0.275)^{(1)}$ & \\
\hline $\mathrm{Ec}-\mathrm{Ec}$ & $0.319(0.001)^{\star(2)}$ & \\
\hline
\end{tabular}

${ }^{*}$ ): Significantly different from zero at 5\%; (1): Pearson correlation; (2): Spearman correlation.

with EC-OF in the right orbit, and with the interorbital distance EC-EC. These correlations were all positive, indicating a direct relationship between the variables analyzed. The significant correlations ranged from 0.202 to 0.366 , values considered to have a low correlation. In both orbits, the only correlation significantly different from zero was observed with MF-EC. This correlation was positive, indicating a direct relationship (0.330), but still not strong.

Table 4 shows the results of the regression of stature concerning the orbital measurements independent of side, interorbital measurements, and sex. Positive coefficients were obtained for MF-EC, MF-OF, EC-OF, OI-OF, MF-MF, EC-EC, and sex. The female sex was the reference for the variable sex (0), being the coefficient equal to 0.089 . The other variables had negative coefficients. The two significant variables were EC-EC and sex. The coefficient of determination was 0.460 , indicating a good fit of the model to the data. Other results not shown in this table demonstrated that the model is significant $(p<0.001)$, and the standardized residuals showed a normal distribution.

Getting the results of Table 4, a backward selection was used, with variables with $p=0.10$ entering and remaining in the model. As shown in this table, EC-EC and sex were the only two variables that remained in the model. Both 
Table 4. Results of stature regression concerning orbital measurements independent of side and interorbital measurements.

\begin{tabular}{|c|c|c|}
\hline Variable & Coefficient & $p$-value \\
\hline Constant & 1.374 & $<0.001^{\star}$ \\
\hline Mf-Ec & 0.001 & 0.306 \\
\hline Os-Oi & -0.003 & 0.418 \\
\hline Mf-Of & 0.001 & 0.735 \\
\hline Ec-Of & 0.003 & 0.428 \\
\hline Os-Of & -0.001 & 0.715 \\
\hline Oi-Of & 0.004 & 0.517 \\
\hline Mf-Mf & 0.001 & 0.494 \\
\hline $\mathrm{Ec}-\mathrm{Ec}$ & 0.002 & $<0.001^{\star}$ \\
\hline Sex & 0.089 & $<0.001^{*}$ \\
\hline
\end{tabular}

Equation: Height ${ }_{\text {est }}=1.374+0.001 \cdot \mathrm{MF}-\mathrm{EC}-0.003 \cdot \mathrm{OS}-\mathrm{OI}+0.001 \cdot \mathrm{MF}-\mathrm{OF}+0.003 \cdot \mathrm{EC}-\mathrm{OF}-$ 0.001·OS-OS + 0.004.OI-OF + 0.001·MF-MF + 0.002.EC-EC + 0.089.Sex; Sex: $0=$ Female; $1=$ Male

${ }^{*}$ : Significant at the $5 \%$ level.

variables had positive and significant coefficients $(p<0.001)$, with female sex $(0)$ being used as the reference. The coefficient of variation was 0.435 , indicating a good fit of the model to the data. Other results not shown in Table 5 demonstrated that the model is significant $(p<0.001)$, and the standardized residuals showed a normal distribution.

Based on the results found and the coefficient of determination of 0.435 for Ec-Ec and sex, the following equation was obtained to establish the subject's stature:

$$
\begin{aligned}
& \text { Equation: Stature } \mathrm{est}_{\mathrm{m})}=1.429+0.002 \cdot \mathrm{EC}-\mathrm{EC}+0.092 \cdot \mathrm{Sex} \\
& \text { Sex: } 0=\text { Female; } 1 \text { = Male }
\end{aligned}
$$

Table 6 shows the area under the ROC curve analysis for the prediction of the numerical measurements in men. It showed that on the right orbit, the Mf-Ec has a high specificity for women, an accuracy for detecting males and females of 61.6. The Ec-Of has a high sensitivity for men and an accuracy of 70.7. On the left orbit, the Mf-Ec has a high specificity for female and an accuracy of 62.6.

\section{Discussion}

The present study analyzed the orbital cavities of adult men and women based on conventional computed tomography scans. Linear distances were measured from craniometric points and correlated with height and sex. An equation was derived from these data for stature estimation based on the acquired measurements. To our knowledge, there are no studies in the literature that analyzed and correlated orbital cavity measurements with stature or proposed an equation model to assist the forensic investigation. 
Table 5. Results of stature regression concerning orbital measurements independent of side and interorbital measurements, selecting variables with $p<0.001$.

\begin{tabular}{|c|c|c|}
\hline Variable & Coefficient & $p$-value \\
\hline Constant & 1.429 & $<0.001^{\star}$ \\
\hline Ec-Ec & 0.002 & $<0.001^{\star}$ \\
\hline Sex & 0.092 & $<0.001^{*}$ \\
\hline Coefficient of determination & & \\
\hline
\end{tabular}

$\left.{ }^{\star}\right)$ : Significant at the $5 \%$ level.

Table 6. Analysis of the area under the ROC curve for the prediction of the numerical measurements in men.

\begin{tabular}{ccccccc}
\hline Variable & $\begin{array}{c}\text { The area under } \\
\text { the curve }\end{array}$ & $p$-value & Cut-off & $\begin{array}{c}\text { Sensitivity } \\
(\%)\end{array}$ & $\begin{array}{c}\text { Specificity } \\
(\%)\end{array}$ & $\begin{array}{c}\text { Accuracy } \\
(\%)\end{array}$ \\
\hline Stature & 0.885 & $<0.001^{*}$ & 1.655 & 84.1 & 83.3 & 83.8 \\
Right orbit & & & & & & \\
Mf-Ec & 0.692 & $0.002^{*}$ & 35.60 & 42.9 & 94.4 & 61.6 \\
Os-Oi & 0.579 & 0.192 & & & & \\
Mf-Of & 0.517 & 0.774 & & & & \\
Ec-Of & 0.642 & $0.019^{*}$ & 15.35 & 92.1 & 33.3 & \\
Os-Of & 0.574 & 0.220 & & & & \\
Oi-Of & 0.491 & 0.884 & & & & \\
Left orbit & & & & & \\
Mf-Ec & 0.636 & $0.025^{*}$ & 35.45 & 49.2 & & \\
Os-Oi & 0.536 & 0.553 & & & & \\
Mf-Of & 0.539 & 0.520 & & & & \\
Ec-Of & 0.578 & 0.200 & & & & \\
Os-Of & 0.533 & 0.583 & & & & \\
Oi-Of & 0.569 & 0.252 & & & & \\
Interorbital & & & & & & \\
Mf-Mf & 0.498 & 0.974 & & & & \\
Ec-Ec & 0.592 & 0.129 & & & & \\
\hline
\end{tabular}

$\left({ }^{*}\right)$ : Significant at $5 \%$.

Several studies have been conducted in different countries to establish reliable parameters for stature estimation from bones, most of them in Europe and more recently in Central and South America (Belmonte et al., 2011; Mbbs \& Mbbs, 2012, Animale, 1993; Giannecchini et al., 2008; Menéndez et al., 2018). However, there are no reliable standards for stature estimation from bones in Brazil. The Brazilian population's wide diversity is so great that it creates groups of individuals with peculiar and unique characteristics within the same country (Pereira et 
al., 2019). In agreement with this fact, Keen (1950) reported that estimating the sex and race from a bone in a previously known group is an easy task, but determining such characteristics in distinct groups becomes an expert task.

One major difficulty encountered in establishing stature is the absence of other bone parts that are lost and/or mutilated. When complete bones are available, the fully method or anatomical method can be adopted as an alternative. An approximation of stature is obtained by summing dimensions of the skeletal elements that contribute directly to height and adding a correction factor for soft tissue (Raxter et al., 2006). However, mathematical models using regression formulae have been suggested for bone fragments since studies have shown that these equations are accurate for stature estimation (Bidmos, 2008; Telkkã, 1950; Trotter \& Gleser, 1958).

Given the importance of stature for the area of human identification and the paucity of studies correlating the anthropometric measurements of height with orbital dimensions, this study aimed to develop a new tool that could facilitate dental/medical work examiners during the identification of cadavers in a Brazilian population. Following the study of Ji et al. (2010), linear measurements were taken to describe the main characteristics of the orbits based on specific anatomical landmarks. Analysis of the mean and standard deviation of the orbital measurements according to the side revealed a significant difference $(p<0.05)$ between sides only for the variable EC-OF. In general, although they present differences, they are minimal and without significant repercussions, corroborating the findings of this study and others in the literature (Pereira et al., 2019; Ji et al., 2010). Although a few studies were found correlating stature and orbital measurements, the literature is scarce in providing studies about this theme in different populations worldwide.

Significant differences were obtained in the mean values of the variables studied, which were higher in males than females. Knowing that the size of the orbit is related to differences in individuals' height and varies significantly according to sex, the size of the orbit was smaller in women compared to men, in agreement with the studies of Ji et al. (2010), Weaver et al. (2010), Yuen et al. (2008) and Pereira et al. (2019). In this regard, the Mf-Ec measurement was highly specific for females, i.e., if the mean of this variable is used for sex identification, the females will be detected in $94 \%$ of cases. Furthermore, it can be as accurate as $70 \%$ to differentiate females from males.

When the orbital measurements were correlated with height, correlations significantly different from zero were observed for height with Ec-Ec and Mf-Ec in the right and left orbit and with MF-OF in the left orbit, ranging from 0.248 to 0.379 . However, analysis of the orbital measurements independent of side showed correlations significantly different from zero for stature with MF-EC and EC-OF. These significant values were all positive, indicating a direct relationship.

The correlations found might be related to the limited number of tomography scans analyzed in this study. However, the variability was low since the standard 
deviations were less than $1 / 3$ of the corresponding means, further strengthening the present study results. Furthermore, predicting stature in males and females in this particular population can be accurate in about $83 \%$ of the cases.

Studies using regression analysis for stature estimation from cranial measurements in the living have concluded that this is an effective tool to estimate total skeletal height (Krishan, 2008; Kamal \& Kumar, 2016; Sahni et al., 2010). A similar conclusion can be drawn in the present study, with the measurements being obtained from the orbit by tomographic analysis. Analysis of the orbital cavity for human identification revealed that this was an important tool for stature evaluation, with regression analysis of stature on the orbital measurements permitting to establish an equation. Independent of the side analyzed, EC-EC and sex remained in the model. Both variables had positive coefficients and were significant $(p<0.001)$.

When analyzing some of the observed patterns and seeking information from similar works, studies evaluating the correlation of craniometric measurements with stature were found to be scarce in the literature. Given the difficulties reported in reliably estimating stature from anthropometric measurements, the introduction of the equation proposed in the present study is a significant contribution.

This study is of paramount importance from an anthropological perspective for increasing tools for identifying Northeastern Brazilian bodies, which will be of great importance in human identification practice at legal medicine institutes to optimize identification in selected cases.

Therefore, future studies validating this regression equation in dry bones or other experimental models are mandatory to increase the reliability of the results so that the equation will be useful in forensic practice. Similar studies involving different populations should also be conducted to verify the applicability of the equation in other populations.

As mentioned before in this study, classically, long bones are preferred for estimating the stature of skeletons. However, in a daily practical context receiving bodies in an advanced stage of decomposition, mutilated, or dismembered for examination is not rare. Also, in mass disasters and mass graves in a humanitarian context, there are real chances that the bodies to be found very fragmented. That is why studies like the present one are essential, once the equation proposed could be easily applied to dry bone fragments when even one of the orbits is still preserved, which would consist of a useful tool for stature estimation.

\section{Conclusion}

Linear orbital measurements are feasible, applicable, and relevant in assessing the stature in images of bone remains for human identification. Individual characteristics (sex and height) were correlated with some of the orbital measurements analyzed. It was possible to establish an equation for estimating the stature of these Brazilian individuals. 


\section{Conflicts of Interest}

The authors declare no conflicts of interest regarding the publication of this paper.

\section{Acknowledgements}

This research had a financial support with Student's Scholarships: PFA-2016/ University of Pernambuco (undergraduate student) and CAPES-2014/2016/ University of Pernambuco (postgraduate student).

\section{References}

Animale, C. (1993). Stature Reconstruction from Long Bones in Ancient Population Samples: An Approach to the Problem of Its Reliability. American Journal of Physical Anthropology, 90, 351-358.

Belmonte, M. T., Sánchez Blanque, J. L., Alemán, I., \& Botella, M. C. (2011). Estimación de la estatura a través de la tibia en población contemporánea española adulta femenina. Cuadernos de Medicina Forense, 17, 83-89. https://doi.org/10.4321/S1135-76062011000200005

Bidmos, M. A. (2008). Metatarsals in the Estimation of Stature in South Africans. Journal of Forensic and Legal Medicine, 15, 505-509. https://doi.org/10.1016/j.jflm.2008.05.007

Giannecchini, M., Moggi-cecchi, J., Antropologia, L., \& Animale, B. (2008). Stature in Archeological Samples from Central Italy: Methodological Issues and Diachronic Changes. The American Journal of Physical Anthropology, 135, 284-292. https://doi.org/10.1002/ajpa.20742

Gidna, A. O., \& Domínguez-Rodrigo, M. (2013). A Method for Reconstructing Human Femoral Length from Fragmented Shaft Specimens. HOMO Journal of Comparative Human Biology, 64, 29-41. https://doi.org/10.1016/j.jchb.2012.09.006

Ji, Y., Qian, Z., Dong, Y., Zhou, H., \& Fan, X. (2010). Quantitative Morphometry of the Orbit in Chinese Adults Based on a Three-Dimensional Reconstruction Method. Journal of Anatomy, 217, 501-506. https://doi.org/10.1111/j.1469-7580.2010.01286.x

Kamal, R., \& Kumar, P. (2016). Estimation of Stature from Different Anthropometric Measurements in Kori Population of North India, Egypt. Journal of Forensic Sciences, 6, 468-477. https://doi.org/10.1016/j.ejfs.2016.12.001

Keen, J. A. (1950). A Study of the Differences between Male and Female Skulls. The American Journal of Physical Anthropology, 8, 79-65. https://doi.org/10.1002/ajpa.1330080113

Krishan, K. (2008). Estimation of Stature from Cephalo-Facial Anthropometry in North Indian Population. Forensic Science International, 181, 52.e1-6. https://doi.org/10.1016/j.forsciint.2008.08.001

Mbbs, M. C., \& Mbbs, V. K. (2012). Reconstruction of Femur Length from Its Fragments in South Indian Males. Journal of Forensic and Legal Medicine, 19, 132-136. https://doi.org/10.1016/j.jflm.2011.12.010

Menéndez, A., Sánchez-mejorada, G., \& Gómez-valdés, J. A. (2018). Stature Estimation Formulae for Mexican Contemporary Population: A Sample-Based Study of Long Bones. Journal of Forensic and Legal Medicine, 54, 87-90.

https://doi.org/10.1016/j.jflm.2017.12.019

Pereira, A. M., Antunes, A. A., Soriano, E. P., Rodrigues, B. H., Pereira, V. B., \& Porto, G. G. (2019). Orbital Cavity Evaluation in a Brazilian Population. Journal of Oral and 
Maxillofacial Radiology, 7, 1-5. https://doi.org/10.4103/jomr.jomr_1_19 http://www.joomr.org/text.asp?2019/7/1/1/259978

Raxter, M. H., Auerbach, B. M., \& Ruff, C. B. (2006). Revision of the Fully Technique for Estimating Statures. The American Journal of Physical Anthropology, 130, 374-384. https://doi.org/10.1002/ajpa.20361

Sahni, D., Sharma, P., Kaur, G., \& Aggarwal, A. (2010). Estimation of Stature from Facial Measurements in Northwest Indians. Legal Medicine, 12, 23-27. https://doi.org/10.1016/j.legalmed.2009.10.002

Telkkã, A. (1950). On the Prediction of Human Stature from the Long Bones. Acta Anatomica, 9, 103-117. https://doi.org/10.1159/000140434

Trotter, M., \& Gleser, G. (1958). A Re-Evaluation of Estimation of Stature Based on Measurements of Stature Taken during Life and of Bones after Death. The American Journal of Physical Anthropology, 16, 79-124. https://doi.org/10.1002/ajpa.1330160106

Weaver, A. A., Loftis, K. L., Tan, J. C., Duma, S. M., \& Stitzel, J. D. (2010). CT Based Three-Dimensional Measurement of Orbit and Eye Anthropometry. Investigative Ophthalmology \& Visual Science, 51, 4892-4897. https://doi.org/10.1167/iovs.10-5503

Yuen, H. K. L., Cheng, A. C. O., Lucas, P. W., Lam, D. S. C., \& So, K.-F. (2008). Surgical Anatomy of the Chinese Orbit. Ophthalmic Plastic \& Reconstructive Surgery, 24, 136-141. https://doi.org/10.1097/IOP.0b013e31816704f5 